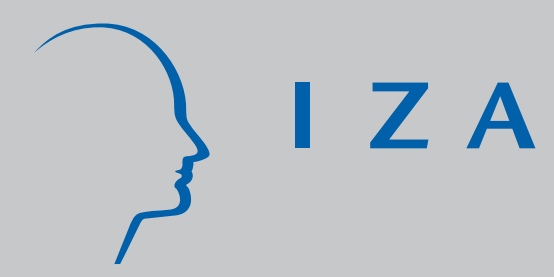

IZA DP No. 1887

Labour Force Participation of the Elderly in Europe: The Importance of Being Healthy

Adriaan Kalwij

Frederic Vermeulen

December 2005 


\title{
Labour Force Participation of the Elderly in Europe: The Importance of Being Healthy
}

\author{
Adriaan Kalwij \\ Utrecht University \\ and IZA Bonn
}

Frederic Vermeulen

Tilburg University, Netspar, CentER

and IZA Bonn

Discussion Paper No. 1887

December 2005

\author{
IZA \\ P.O. Box 7240 \\ 53072 Bonn \\ Germany \\ Phone: +49-228-3894-0 \\ Fax: +49-228-3894-180 \\ Email: iza@iza.org
}

\begin{abstract}
Any opinions expressed here are those of the author(s) and not those of the institute. Research disseminated by IZA may include views on policy, but the institute itself takes no institutional policy positions.

The Institute for the Study of Labor (IZA) in Bonn is a local and virtual international research center and a place of communication between science, politics and business. IZA is an independent nonprofit company supported by Deutsche Post World Net. The center is associated with the University of Bonn and offers a stimulating research environment through its research networks, research support, and visitors and doctoral programs. IZA engages in (i) original and internationally competitive research in all fields of labor economics, (ii) development of policy concepts, and (iii) dissemination of research results and concepts to the interested public.
\end{abstract}

IZA Discussion Papers often represent preliminary work and are circulated to encourage discussion. Citation of such a paper should account for its provisional character. A revised version may be available directly from the author. 
IZA Discussion Paper No. 1887

December 2005

\section{ABSTRACT}

\section{Labour Force Participation of the Elderly in Europe: The Importance of Being Healthy}

In this paper we study labour force participation behaviour of individuals aged 50-64 in 11 European countries. The data are drawn from the new Survey of Health, Ageing and Retirement in Europe (SHARE). The empirical analysis shows that health is multidimensional, in the sense that different health indicators have their own significant impact on individuals' participation decisions. Health effects differ markedly between countries. A counterfactual exercise shows that improved health conditions may yield over 10 percentage points higher participation rates for men in countries like Austria, Germany and Spain, and for females in the Netherlands and Sweden. Moreover, we show that the declining health condition with age accounts considerably for the decline in participation rates with age.

JEL Classification: I10, J22, J26

Keywords: $\quad$ SHARE, labour force participation, health, retirement

Corresponding author:

Frederic Vermeulen

Tilburg University

P.O. Box 90153

NL-5000 LE Tilburg

The Netherlands

Email: frederic.vermeulen@uvt.nl

\footnotetext{
* We are grateful to Rob Alessie and Martin Browning, as well as seminar participants in Leuven, Tilburg and at the RTN-AGE workshop in Venice for useful comments and suggestions. The authors acknowledge the financial support provided through the European Community's 5th framework programme under the project name AMANDA (QLK6-CT-2002-002426).
} 


\section{Introduction}

Population ageing is considered to be one of the most important social and economic challenges in Europe in the next decades. Life expectancy has been increasing markedly since more than a century, while fertility has been declining. At the same time, most industrialized countries were subject to sweeping changes in their labour markets. Female labour force participation has increased over time, resulting in a shrinking gap between male and female participation rates. At the same time, however, workers retire at younger ages than they used to do. These features imply a big uncertainty concerning the long term sustainability of public pension programmes in European countries (see Banks et al., 2002 for a discussion).

It goes without saying that considerable attention has been devoted to these issues by policy makers and researchers. One basic requirement for a sound analysis of the ageing problem is, of course, the availability of adequate data sources. In this respect, many European countries are lagging behind the United States that has a tradition in gathering data on elderly persons; think, for instance, of the widely explored Retirement History Study and its successor the Health and Retirement Study. Recently, however, Europe partly made up arrears by establishing the Survey of Health, Ageing and Retirement in Europe (SHARE) covering 11 European countries. ${ }^{1}$

SHARE contains data on the individual life circumstances of a representative sample of about 18,000 households with at least one household member aged 50 or over. The survey covers such issues like labour force participation, a wide range of physical and mental health indicators, socioeconomic situation and family and social networks (see Börsch-Supan et al., 2005 for a sample of the issues covered by SHARE). The first wave of SHARE, which is designed to be a longitudinal survey, contains data that was gathered in 2004 and was publicly released in Spring 2005. Given the availability of only one wave up to now, SHARE will expose its full strength in a couple of years when the next waves will be available. Nevertheless, its cross-national and its truly multidisciplinary dimension, two features which make the dataset unique, are immediately exploitable.

In this study, we take a closer look at the labour force participation of men and women aged 50-64 (both years included) in Europe. Although our study is primarily meant to be descriptive, we also want to explore which individual and demographic

\footnotetext{
${ }^{1}$ This paper uses data from the early release 1 of SHARE 2004. This release is preliminary and may contain errors that will be corrected in later releases. The SHARE data collection has been primarily funded by the European Commission through the 5th framework programme (project QLK6CT-2001-00360 in the thematic programme Quality of Life). Additional funding came from the US National Institute on Aging (U01 AG09740-13S2, P01 AG005842, P01 AG08291, P30 AG12815, Y1AG-4553-01 and OGHA 04-064). Data collection in Austria (through the Austrian Science Fund, FWF), Belgium (through the Belgian Science Policy Office) and Switzerland (through BBW/OFES/UFES) was nationally funded. The SHARE data set is introduced in Börsch-Supan et al. (2005).
} 
characteristics have an impact on individual participation decisions. A wide variety of variables affecting individual retirement behaviour have been studied in the theoretical and empirical literature. As illustrated by Gruber and Wise (1998, 2002, 2005), an important set of such variables relate to incentives inherent in a country's social security provisions. At this stage, though, SHARE does not allow to calculate detailed incentive measures such as the accrual in social security wealth by working one more year or Stock and Wise's (1990) option value of postponing retirement. ${ }^{2}$ Also the health status is supposed to have an important impact on an elderly individual's participation decision (see Lumsdaine and Mitchell, 1999, for a theoretical discussion of this linkage). Usually, a single health indicator appears in equations describing labour supply decisions of the elderly (see Rust and Phelan, 1997, Blundell et al., 2002 and Gustman and Steinmeier, 2005 for only a few examples). A widely chosen health indicator in such analyses is the self-reported health status. It is well-known, however, that self-reported health is likely to be endogenous. Think, for example, of justification bias, where individuals may justify their non-participation by claiming that they are in ill-health. In order to tackle this endogeneity problem, some authors instrument self-reported health by more objective variables related to an individual's health to obtain a single exogenous health indicator (see Bound et al., 1999, Kerkhofs et al., 1999, and Disney et al., 2004). An aspect that has been widely ignored, however, is that health may be multi-dimensional. Different health indicators may have a divergent impact on an individual's participation decision. While a severe health condition like cancer or a stroke may force an individual to leave the labour market, this is not necessarily the case for mild conditions such as high blood pressure or diabetes. At this point, the multi-disciplinary nature of SHARE turns out to be very useful. The data set not only contains the standard self-reported health status, but also a wide range of more objective health indicators. Some of the latter, like an individual's grip strength, are commonly used in the medical sciences but usually not surveyed in the social sciences.

The contribution of our study is twofold. First, we will briefly introduce the new SHARE data and shed some light on systematic differences in participation rates and health across the countries involved. This is not only interesting in its own right, but also because of SHARE's advantage that the same survey methodology is applied to all participating countries. Second, we will analyse how labour force participation of the elderly is affected by demographic and health related characteristics. Since SHARE contains only one wave up to now and the data do not yet allow to calculate detailed incentive measures, our study is restricted to a static reduced form analysis of the determinants of labour force participation of the elderly in Europe. Nevertheless, knowing

\footnotetext{
${ }^{2}$ In the future, there will be a link established between SHARE and the social security administration of some countries, which will allow to calculate detailed pension benefits an individual will be eligible to when she or he stops working. On its turn this will allow to take into account incentive measures. (Compare to the link between the HRS and the US Social Security Adminstration).
} 
which variables are significantly associated with labour force participation is a first important step towards a more advanced analysis on longitudinal data. In this respect, the contribution of our study to the existing empirical literature is that our analysis focuses attention on variables, and in particular health related variables, that potentially influence labour force participation of the elderly but that are often neglected in empirical analyses.

The rest of the paper unfolds as follows. Section 2 presents the data and descriptive statistics on labour market behaviour and health of the elderly. Section 3 provides a reduced form analysis of the determinants of labour force participation of the elderly. Section 4 concludes.

\section{Data and descriptive statistics}

The Survey of Health, Ageing and Retirement in Europe (SHARE) is a multi-disciplinary and cross-national dataset that contains information on the individual life circumstances of, in principle, all eligible members of about 18,000 households. A household is eligible for participation in SHARE if at least one household member is born in or before 1954 . An individual member of the household is eligible for interview if she or he, or her or his partner, is born in or before 1954. The SHARE data have been gathered in 2004 and is a random sample of the target population. ${ }^{3}$ The resulting SHARE survey contains information on a wide range of health indicators and socioeconomic variables of over 26,000 individuals. SHARE covers 11 countries: Austria, Belgium, Denmark, France, Germany, Greece, Italy, the Netherlands, Spain, Sweden and Switzerland. The dataset is designed after the Health and Retirement Study (HRS) and the English Longitudinal Study of Ageing (ELSA). Its cross-national dimension makes it a unique and particularly interesting dataset in comparison to other microdata focusing on the elderly.

In this study, we focus on the labour force participation of men and women aged 50 to 64 (both years included). Although there is an important number of individuals that are older in the dataset, policies that aim to increase labour force participation of the elderly probably do not target this group. For example, one of the targets in the Lisbon Strategy is to have an employment rate of 50 percent for individuals aged 55-64 by 2010 (see European Commission, 2004). In Table 4.1, we show some basic statistics on the sample that we selected from SHARE. After dropping individuals that are younger than 50 (partners of an individual who is 50+) or older than 64 (around 48 percent of the sample), and deleting observations with important missing information (3 percent of the remaining sample), we retain a sample of 12,237 observations. Sample size varies considerably across countries (see Table 4.1); countries like Belgium, Germany, the Netherlands and Sweden have around 1500 observations while the other countries,

\footnotetext{
${ }^{3}$ The data from Belgium and France were collected in 2004/2005.
} 
with the exception of Greece, have less than 1000 observations.

The last three columns of Table 4.1 show the percentages of individuals in three age classes. These age classes contain about one third of the selected sample, although there is quite some variation across countries. This variation partly reflects the different age composition in the SHARE-countries, but may also be partly due to under- or overrepresentation of certain age groups. ${ }^{4}$

\section{Table 4.1 about here.}

As already mentioned in the introduction, SHARE contains a lot of health information. In what follows, we focus attention on eight different health indicators. These range from objective measures like an individual's maximum grip strength to the more subjective health measure indicating whether or not one has a good self-perceived health.

Summary statistics on the health variables are given in Tables 4.2 and 4.3. About 14.5 percent of individuals aged 50-64 ever had a severe condition such as a heart condition, a stroke, cancer or Parkinson. The extremes are covered by Belgium (about 17.5 percent) and Switzerland (9.8 percent). It is difficult to claim that this is due to the age composition since the Belgian subsample is slightly younger than the Swiss (see Table 4.1). More than 60 percent of the sample ever had a mild condition (cholesterol, diabetes, arthritis, high blood pressure, etc.; see Smith, 1999, for a classification). The extremes are again Belgium (68.0 percent) and Switzerland (45.6 percent). About 38 percent of the individuals in the selected sample suffer from restrictions in activities of daily living (ADLs; walking 100 meter, bathing or showering, dressing, getting in or out of bed, etc.). This is quite high given that we do not focus on the oldest old in this study. Note the 20 percentage point difference between Austria and Switzerland. Part of this difference can be explained by the relatively older Austrian subsample. One relatively new health measure in social surveys is the maximum grip strength (the scale is from 0 to 100). It is recognized that this health variable, which is known to be correlated with mental as well as physical health, is a very good indicator of an individual's general health condition (see, for example, Christensen, Mackinnon, Korten and Jorm, 2001). The differences in the average across countries is almost 8 points.

Two other health measures are defined by means of the body-mass index (BMI). A BMI that is between 25 and 30 points out that an individual suffers from overweight. It turns out that this is the case for about 42 percent of the Europeans aged 50-64. A $\mathrm{BMI}$ that is above 30 indicates obesity, which is the case for 17 percent of the sample. Taken together, about 60 percent of the elderly in our sample suffers from a weight that is too high.

\footnotetext{
${ }^{4}$ To correct for this one could use sample weights. These were, however, not yet available for the complete SHARE data when starting this study.
} 
Further, about one fifth of the individuals aged 50-64 suffers from more than three bad mental health symptoms like a depression, pessimism, suicidality or guilt. Extremes are formed by France (30.7 percent) and Germany (15.2 percent). Finally, about 73 percent of the individuals in our selected sample have a good self-perceived physical health. ${ }^{5}$

Table 4.2 about here.

Table 4.3 about here.

As illustrated in Blanchet, Brugiavini and Rainato (2005), the transition from full time employment to full time inactivity has become less relevant over the last decades. The standard pattern to retirement has been supplemented by alternative pathways, where an individual may be unemployed, pre-retired or on sickness or disability insurance before actually retiring and drawing most resources from pension benefits. Given the wide variety of systems that persons aged 50 and over can make use of to bridge the period between regular employment and retirement, it can be argued that it is useful to focus on labour force participation and lumping together other social states like being unemployed or on disability insurance. In this study, we consider an individual as participating in the labour market if she or he has worked for pay either as an employee or as a self-employed during the four weeks preceding the interview.

Table 4.4 shows participation rates for men in the SHARE countries. These participation rates are given for three different age classes. As is clear from the table, there is quite some variation in labour force participation across age classes and countries. For example, in the Nordic countries (Denmark and Sweden) and in Switzerland, participation of men aged 55-64 is relatively high, with levels far above the Lisbon target (across gender) of 50 percent. In Belgium, participation for the same age group is less than 40 percent. As could be expected, participation is higher for men aged 50-54, although here too there is considerable variation between the different countries. Similar figures for women are provided by Table 4.5. Participation of women is lower than that of men at the country level and for the different age groups. The notable exception here are French women; we have no explanation for this. Roughly speaking, for women the same broad tendencies between countries can be observed as for men. For example, labour force participation is highest in the Nordic countries and Switzerland, while it is lowest in Belgium.

Table 4.4 about here.

Table 4.5 about here.

\footnotetext{
${ }^{5}$ Unlike ELSA, SHARE does not contain biomedical data on health or bio-markers (see Banks and Kumari, 2005, for an illustration of the usefulness of such variables in retirement studies).
} 
Another issue concerns the prevalence of part time work among the elderly in SHARE. Tables 4.6 and 4.7 give the percentages of individuals not participating, working part time and working full time. An individual is defined to work part time if her or his average weekly labour supply does not exceed 32 hours. It is clear from the tables that part time work is more common for women than for men (percentages across all countries are respectively equal to 19.4 and 8.2 percent). However, there is quite some variation between countries. While only 2.5 percent of Austrian men between 50 and 64 work part time, this is the case for about 13 percent of Dutch and Greek men. A similar variation can be observed for elderly women in Europe. In the Netherlands and Switzerland, more than 30 percent of women aged 50-64 work part time. Also in Denmark, Germany and Sweden part time working women are quite common, where percentages are observed of above 20. In the Southern countries (Greece, Italy and Spain), part time work for elderly women is less common, with percentage rates below 10. A question that could be rightfully asked is whether individuals decrease the amount of hours worked if they get older. Therefore, we also calculated the hours choices of men and women for the three age classes that we used above. ${ }^{6}$ However, it turns out that there is no evidence for diminishing working hours with age. Part time work seems to be more common for Swedish men in the oldest age classes. In the other countries, no clear pattern is observed. Of course, it should be remarked that convincing evidence with respect to the above question can only be obtained by longitudinal data were labour supply transitions of the same individuals are observed.

Table 4.6 about here.

Table 4.7 about here.

Several factors may have their influence on the different participation rates across European countries; these range from a country's particular institutional context, like its normal retirement age, possibilities for early retirement schemes and how labour income is taxed when an individual receives a pension, to variables that are individual-specific such as an individual's health status or education level. In the next section, we will model labour force participation and analyse its determinants by means of a reduced form approach.

\section{Estimation results}

\subsection{Introduction}

We focus on the extensive margin of the labour supply decision. More specifically, we model the choice between not working and working. Given the data at hand, this is

\footnotetext{
${ }^{6}$ Statistics can be obtained from the authors at request.
} 
probably the most relevant dimension to further investigate (see also Section 2). To describe the individual participation decision, we make use of standard probit regressions. These regressions are separately applied to each of the SHARE countries, and apart for men and women. This allows us to let the data speak as much as possible for themselves. Recall that we are forced to leave out incentive measures. Consequently, we focus on non-financial individual characteristics in a reduced form analysis.

We make a distinction between three sets of explanatory variables. A first set of regressors are yearly age dummies. This level of detail allows us to partly capture the countries' social security characteristics that are defined in terms of an individual's age (think for example of the normal retirement age or arrangements for early retirement). A second set of explanatory variables relate to an individual's health status. As already mentioned a couple of times, SHARE contains a wide range of health variables. Not all of these variables, however, are fit to take up in the probit regressions. More specifically, in what follows, we restrict attention to health indicators that are, in general, exogenous in an individual's participation decision. This rules out variables like self-reported health or mental health status. Although there can always be found more or less convincing stories to illustrate potential endogeneity problems, we think that we are on quite safe ground by using health variables like maximum grip strength or dummies capturing whether or not an individual ever had a severe condition or restrictions in activities of daily living in the econometric analysis. A final set of regressors that we focus on capture an individual's socio-demographic situation, like her or his education level, marriage status or number of children.

In what follows, we will first discuss estimation results obtained for men, to continue with the same results for women. To assess the importance of the different health variables, we will conduct a counterfactual exercise which responds to the question how participation rates would look like if everybody was healthy.

\subsection{Results for men}

Tables 4.8 and 4.9 show the estimation results for men aged 50-64. To ease interpretation, we give the marginal effects (along with their standard errors) associated with the different regressors. These are defined as the percentage change of the probability that an individual works for pay due to a marginal (discrete) increase of the associated continuous (dummy) variable. The bottom line of the tables shows the predicted participation probabilities of a man with average characteristics in a given country. Note that most of the regressors are dummy variables. The only exceptions are the grip strength and the number of children. To compare their relative importance, we standardized these variables (by subtracting their means and dividing by their standard deviations). Consequently, their marginal effects are associated with the effect on participation when they increase by one standard deviation. 
Let us first focus attention on the age dummies. Although the normal retirement ages are at least 65 in the countries that we focus on, it is clear from the tables that many age dummies are significantly different from zero, while they generally increase in importance for older individuals. ${ }^{7}$ This is probably due to the existence of age specific early retirement and disability schemes in most countries. The probit results show that the age dummies do not start having any impact before the age of 56: the associated marginal effects are small in absolute value and not significantly different from zero for all countries. A significant age effect can be observed as soon as an individual is 56 in Austria, Belgium and Italy. Especially in Austria, this effect is rather important: the probability that an Austrian man of age 56 participates is 44 percentage point lower than the participation probability of a similar 50 year old man. In countries like Germany, the Netherlands and Spain, there is only a significant impact of the age dummies associated with ages that are at least equal to 60. A remarkable result is obtained for Sweden. Although the marginal effects get smaller for older ages, none of these is significantly different from zero. This implies that, everything else constant, age does not seem to have any impact before an individual reaches the normal retirement age in Sweden.

The second set of regressors that we have a closer look at are health related variables. Before we enter into a detailed analysis of the impact of health on participation, it should be stressed that we do not focus on the oldest old in this analysis. Consequently, the prevalence of some health conditions is rather small, which may have an impact on the importance and significance of estimated parameters.

It turns out that having experienced a severe health condition has a significantly estimated negative impact on a man's labour force participation in about half of the SHARE countries. The economic impact of a severe condition varies in a quite important way between countries. In Germany, the probability of participation is about 13 percentage point lower for a man who experienced a severe condition compared to an individual who never had a severe condition and who is in all other aspects equal. In Austria, the similar percentage point decrease in participation amounts to more than 30. Note that this relatively large difference may be due to the particular composition of the countries' subsamples that are characterized by a severe condition. As could be expected, the impact of a mild condition is less important. Only in Germany, there is a significant negative impact of having experienced a mild condition: a man who ever had a mild condition has a probability of working that is, all else equal, 8 percentage point lower than that of someone without such condition. Having restrictions in activities of daily living, on the other hand, has a significant and economically important impact in Denmark, Germany, the Netherlands, Spain and Sweden, with percentage point impacts between -10 and -26 . Obesity, on its turn, has only in Italy a significant impact,

\footnotetext{
${ }^{7}$ Not all age dummies could be taken into account for France and Switzerland, the reason being that some of these were perfectly correlated with participation/non participation. Problematic age dummies, together with the associated observations, were dropped.
} 
where obese men are 13 percentage point less likely to work than similar men that are not obese. A new health indicator in social surveys is the maximum grip strength of an individual. As is clear from the results, the indicator is quite important in most of the countries in the analysis. All else equal, the higher an individual's grip strength, the more he is likely to participate to the labour market. In Austria, for example, an increase of one standard deviation in grip strength, implies a higher probability of working of about 10 percentage point. For Swedish men, the impact is economically less important, with a marginal effect of about 4 percentage point.

The above results clearly demonstrate that health is multi-dimensional: different health indicators have their own, and divergent, impact on the participation rate. In Germany, for example, all but one of the health variables taken up in the analysis have a significant impact on participation. A qualitatively similar conclusion can be drawn for most other countries in the analysis. Focusing on only one health indicator in empirical analyses may thus obtain biased results. Note, however, that in France, Greece and Switzerland, there are no health variables that are individually significant. We also conducted a Wald test to check whether the null hypothesis of no impact at all of health could be rejected. The second column of Table 4.10 shows the probability values associated with this null hypothesis for men in each of the 11 countries in SHARE. As is clear from the test results, the null hypothesis of no general impact of health is strongly rejected in most countries. Only for Greece and Italy, the null hypothesis cannot be rejected at any reasonable significance level.

A final set of estimates refer to an individual's socio-demographic characteristics. The estimation results indicate that education plays a rather important role in the participation decision. All else equal, the higher the level of education, the higher the probability of participation. Remarkably, in Greece, Spain, Sweden and Switzerland, education does not seem to affect participation in a significant way. ${ }^{8}$ The impact of a household's demographic composition is not extremely important. Although, ceteris paribus, more children imply a higher probability of participation, this is only significantly estimated in Austria, Belgium, France and Sweden. Finally, only in the Nordic countries (Denmark and Sweden), the parameter associated with the dummy variable that captures whether or not a man lives in a couple is significantly estimated. All else equal, Danish (Swedish) men who live in a couple have a participation probability that is 17 (13) percentage point higher than that of men who are single.

Table 4.8 about here.

Table 4.9 about here.

\footnotetext{
${ }^{8}$ This is also formally confirmed by means of a Wald test associated with the null hypothesis that both education dummies do not have any joint impact on participation.
} 
Table 4.10 about here.

\subsection{Results for women}

Marginal effects and standard errors associated with the probit regression results for women aged 50-64 are shown in Tables 4.11 and 4.12. Predicted probabilities that a woman works for pay are given in the bottom line of both tables. ${ }^{9}$

Similar to the men's results, many age dummies have a significant negative impact on participation. However, these effects start earlier: in Belgium and Spain, women who are 54 years old are about 20 percentage point less likely to work compared to a 50 years old woman. In Germany and the Netherlands, age comes into play as soon as a woman reaches the age of 60 (as was also the case for German and Dutch men). Contrary to the estimation results for men, there are no countries that are characterized by absence of any age effects.

As above, many health indicators have their own significant impact on women's participation decisions. However, there is quite an important variation between countries. While not any single health variable has a significant impact on the probability of working for pay in Austria, in countries like the Netherlands and Sweden, four out of the five health indicators have an own significant effect. These effects are in line with those obtained for men. To investigate the joint impact of health on participation, we also conducted a Wald test associated with the null hypothesis that there is no joint impact of all the health related variables. Results for women are provided in the last column of Table 4.10. As the results indicate, only in Austria and Greece, the null hypothesis of no joint impact cannot be rejected at any reasonable significance level.

The impact of education is both economically and statistically significant for all countries: higher education implies a, ceteris paribus, higher probability of working for pay. ${ }^{10}$ The lowest education impact is observed in Sweden, where highly educated women are 11 percentage point more likely to participate than low educated women, all else equal. In Italy, highly educated women have a probability of participation that is even 47 percentage point higher than otherwise similar low educated women. This seems to indicate that education plays a bigger role in the participation decision for women than for men.

Other striking differences can be observed for the regressors that are related to a household's demographic composition. All else equal, in many countries women have a lower probability to participate if they live in a couple (up to about 20 percentage

\footnotetext{
${ }^{9}$ The age dummy associated with the age of 64 could not be taken into account for Belgium, since it is perfectly correlated with non participation. This problematic variable, together with the associated observations, were dropped.

${ }^{10}$ Although both dummies associated with education are not significantly different from zero for France, the null hypothesis of their joint insignificance is rejected at the 5 percent significance level.
} 
point in France and Spain) and/or if there are children present in the household. Given the positive impact of the dummy variable associated with living in a couple and the number of children in many of the men's equations, this could indicate that there is some coordination going on within couples: on average men seem to specialize in market work while women stay home and take care for the children.

Table 4.11 about here.

Table 4.12 about here.

\subsection{Counterfactual exercise}

To better assess the quantitative importance of health in an individual's participation decision, we conduct a counterfactual exercise in what follows. More specifically, we ask ourselves what would be the participation rates in each of the analysed countries if their populations of individuals aged 50-64 would be in perfect health. Concretely, this exercise implies the comparison between the current participation rates and the estimated participation rates that are obtained by replacing observed health indicators by health indicators that are characteristic for individuals who are in perfect health. Perfect health is here defined as (1) never had a severe condition, (2) never had a mild condition, (3) no ADLs, (4) not being obese and (5) having a grip strength of an average (fe)male individual who is aged 50-51. It should be remarked that the results in this exercise are driven by two factors: both relatively low estimated probit coefficients (in absolute values) and relatively healthy populations may result in a negligible impact on participation of the counterfactual exercise.

The results of this exercise for the whole sample can be found in Tables 4.13 and 4.14. For men, the impact of health, measured by the increase in a country's expected participation rate, is rather important. In countries like Germany and Spain, participation would be about 12 percentage point higher if every men, all else equal, would be perfectly healthy. Even in countries that already have a relatively high participation rate, like Sweden, participation could increase by about 7 percentage point if all men were healthy. In Greece, Italy and Switzerland, the impact of health is less important, with percentage point increases, with respect to current participation rates, of less than 3 .

Also for women, the impact of health is quite important. Similar to men, there is some variation between countries. In Austria and Switzerland, participation rates would increase by less than 2 percentage point if all women were in perfect health. On the other hand, in Sweden, the overall participation rate would increase by 12 percentage point. This is especially remarkable since Sweden has the highest current participation rate for women. 
Table 4.13 about here.

Table 4.14 about here.

The above discussed figures, though, hide the variation between age groups of the impact of health. Therefore, in Tables 4.15 and 4.16, we also show the counterfactual results for individuals aged 50-54, individuals aged 55-59 and the oldest individuals in our sample who are aged 60-64. For most countries, the difference between the current and counterfactual participation rate of men increases over the three age categories (exceptions are Austria, Belgium, France and Italy). In Germany and Spain, the difference between current and counterfactual participation is about 6 percentage point for men aged 50-54. For the oldest group of men in the sample, this difference amounts to respectively 18 and 19 percentage point. Although less pronounced, a similar pattern can be observed for most of the other countries. For women, such a clear pattern over the different age groups can only be observed for Denmark and Sweden. This, of course, does not imply that health is not important as a participation determinant for women; it merely indicates that its impact does not change very much over different age groups.

Tables 4.15 and 4.16 also allow calculating how much of the total decline in participation rates with age can be accounted for by a declining health condition with age. This measure is obtained by taking the difference of the differences in counterfactual participation and current participation of individuals aged 60-64 and individuals aged 50-54, and dividing this by the absolute difference in current participation of both age groups. Results are given in Table 4.17. As the table indicates, more than one third of the decline in male participation is due to health in Sweden and Switzerland. Also in Denmark, Germany and Spain, this impact is quite substantial, where a deteriorating health condition with age accounts for more than 20 percent of the observed decline in participation. For women, the impact of health on the observed decline in participation is generally lower. An exception is Sweden (and to a lesser extent Switzerland) where about 40 percent (18 percent) of the observed decrease in participation is due to a worse health when women get older.

Table 4.15 about here.

Table 4.16 about here.

Table 4.17 about here.

\section{Conclusion}

In this paper, we studied labour force participation behaviour of elderly individuals in Europe. The data used were drawn from the first wave of the new Survey of Health, 
Ageing and Retirement in Europe (SHARE). This survey, which is designed as a longitudinal survey, contains detailed data on the life circumstances of a representative sample of individuals aged 50 and over in 11 European countries. Its cross-national and multi-disciplinary nature makes it a very valuable source for all kinds of social and economic analyses.

A general result of this study is that the multi-dimensional nature of the health condition of individuals is of major importance when studying its effect on labour force participation. Different health indicators have a significantly different impact on an individual's participation. This implies that models focusing on only one health indicator may miss an important dimension in elderly individuals' participation decisions. We also illustrated the economic importance of a good health by estimating participation rates corresponding with a population that was in perfect health. The results indicated that in most countries participation would increase considerably if every individual aged 50-64 would be in perfect health. Participation of men would be up to 10 percentage points higher in countries like Austria, Germany and Spain, while a similar figure is obtained for females in the Netherlands and Sweden. Moreover, we find that the declining health condition with age accounts susbstantially for the decline in male and female participation rates with age.

Since the SHARE data contain a single wave up to now, its full potential will only be exploitable in the future. Once several waves will be available, a more advanced modelling of individuals' labour supply decisions will become possible. One aspect that was only tackled rather marginally in this study, is that there could be some coordination going on in households. We found, for example, that men who live in a couple and who have children are more likely to work than single men without children. The reverse conclusion could be drawn for women. This may indicate that men and women in couples coordinate their labour supply in the sense that men specialize in market work while women engage relatively more in home work (including care for the children). Note that this sheds some new light on earlier evidence found in the literature that husbands and wives seem to coordinate their retirement decisions (see Blau, 1998, Gustman and Steinmeier, 2000 and Michaud en Vermeulen, 2004). Clearly, future SHARE waves will allow investigating this issue in a more detailed way.

\section{References}

[1] Banks, J., R. Blundell, R. Disney and C. Emmerson (2002), "Retirement, pensions and the adequacy of saving: A guide to the debate", IFS Briefing Note, 29, Institute for Fiscal Studies, London.

[2] Banks, J. and M. Kumari (2005), "Health and retirement in England: New evidence from the English Longitudinal Study of Ageing", mimeo. 
[3] Blanchet, D., A. Brugiavini and R. Rainato (2005), "Pathways to retirement", in A. Börsch-Supan, A. Brugiavini, H. Jürges, J. Mackenbach, J. Siegrist and G. Weber (eds.), Health, Ageing and Retirement in Europe. First Results from the Survey of Health, Ageing and Retirement in Europe, Mannheim Research Institute for the Economics of Ageing, Mannheim, 246-252.

[4] Blau, D. (1998), "Labor force dynamics of older married couples", Journal of Labor Economics, 16, 595-629.

[5] Blundell, R., C. Meghir and S. Smith (2002), "Pension incentives and the pattern of early retirement", Economic Journal, C153-C170.

[6] Bound, J. M. Schoenbaum, T. Stinebrickner and T. Waidmann (1999), "The dynamic effects of health on the labor force transitions of older workers", Labour Economics, 6, 179-202.

[7] Börsch-Supan, A., A. Brugiavini, H. Jürges, J. Mackenbach, J. Siegrist and G. Weber (eds.), Health, Ageing and Retirement in Europe. First Results from the Survey of Health, Ageing and Retirement in Europe, Mannheim Research Institute for the Economics of Ageing, Mannheim.

[8] Christensen, H., A. Mackinnon, A. Korten and A. Jorm (2001), "The "common cause hypothesis" of cognitive aging: Evidence for not only a common factor but also specific associations of age with vision and grip strength in a cross-sectional analysis", Psychology and Aging, 16, 588-599.

[9] Disney, R., C. Emmerson and M. Wakefield (2004), "Ill health and retirement in Britain: A panel data based analysis", forthcoming in Journal of Health Economics.

[10] European Commission (2004), Report from the Commission to the Spring European Council. Delivering Lisbon. Reforms for the Enlarged Union, Commission of the European Communities, Brussels.

[11] Gruber, J. and D. Wise (1998) (Eds.), Social Security Programs and Retirement around the World, University of Chicago Press, Chicago.

[12] Gruber, J. and D. Wise (2002), "Social security programs and retirement around the world: Micro estimation", NBER Working Paper 9407, NBER, Cambridge.

[13] Gruber, J. and D. Wise (2005), "Social security programs and retirement around the world: Fiscal implications. Introduction and summary", NBER Working Paper 11290, NBER, Cambridge. 
[14] Gustman, A. and T. Steinmeier (2000), "Retirement in dual-career families: a structural model", Journal of Labor Economics, 18, 503-545.

[15] Gustman, A. and T. Steinmeier (2005), "The social security early entitlement age in a structural model of retirement and wealth", Journal of Public Economics, 89, 441-463.

[16] Kerkhofs, M., M. Lindeboom and J. Theeuwes (1999), "Retirement, financial incentives and health", Labour Economics, 6, 203-227.

[17] Lumsdaine, R. and O. Mitchell (1999), "New developments in the economic analysis of retirement" in O. Ashenfelter and D. Card (eds.), Handbook of Labor Economics. Volume 3, Elsevier, Amsterdam.

[18] Michaud, P.-C. and F. Vermeulen (2004), "A collective retirement model: identification and estimation in the presence of externalities", CentER Discussion Paper 2004-75, CentER, Tilburg University.

[19] Rust, J. and C. Phelan (1997), "How social security and medicare affect retirement behavior in a world of incomplete markets", Econometrica, 65, 781-831.

[20] Smith, J. (1999), "Healthy bodies and thick wallets: the dual relation between health and economic status", Journal of Economic Perspectives, 13, 145-166.

[21] Stock, J. and D. Wise (1990), "Pensions, the option value of work and retirement", Econometrica, 58, 1151-1180. 


\begin{tabular}{|l|c|c|c|c|}
\hline Country & Observations & Age 50-54 & Age 55-59 & Age 60-64 \\
\hline Austria & 882 & 27.21 & 32.43 & 40.36 \\
Belgium & 1511 & 38.19 & 36.00 & 25.81 \\
Denmark & 866 & 35.22 & 34.76 & 30.02 \\
France & 785 & 38.73 & 36.31 & 24.97 \\
Germany & 1450 & 35.24 & 28.69 & 36.09 \\
Greece & 1098 & 42.08 & 31.24 & 26.68 \\
Italy & 1205 & 25.06 & 37.34 & 37.59 \\
The Netherlands & 1544 & 32.71 & 37.37 & 29.92 \\
Spain & 971 & 33.88 & 34.09 & 32.03 \\
Sweden & 1464 & 30.12 & 37.09 & 32.79 \\
Switzerland & 461 & 38.83 & 30.37 & 30.80 \\
\hline Total & 12,307 & 33.95 & 34.45 & 31.59 \\
\hline
\end{tabular}

Table 4.1: Sample statistics and age classes Note: Entries for age classes are in percent.

\begin{tabular}{|l|c|c|c|c|}
\hline Country & Severe condition & Mild condition & ADLs & Max. grip strength \\
\hline Austria & 12.02 & 56.69 & 44.22 & 39.26 \\
Belgium & 17.54 & 67.97 & 41.56 & 38.82 \\
Denmark & 17.21 & 62.36 & 31.99 & 40.29 \\
France & 14.14 & 62.29 & 34.27 & 37.26 \\
Germany & 14.76 & 59.59 & 40.41 & 39.97 \\
Greece & 9.93 & 55.28 & 41.44 & 36.99 \\
Italy & 14.19 & 65.98 & 41.08 & 34.23 \\
The Netherlands & 17.42 & 54.99 & 35.23 & 39.13 \\
Spain & 12.98 & 67.04 & 43.98 & 32.28 \\
Sweden & 14.62 & 60.52 & 32.59 & 38.41 \\
Switzerland & 9.76 & 45.55 & 24.51 & 39.00 \\
\hline Total & 14.54 & 60.62 & 38.09 & 37.85 \\
\hline
\end{tabular}

Table 4.2: Health indicators Part 1

Note: Occurrence of conditions and ADLs in percent; maximum grip strength in kg. 


\begin{tabular}{|l|c|c|c|c|}
\hline Country & Overweight & Obese & Bad mental health & Good self-perceived health \\
\hline Austria & 42.29 & 21.54 & 15.76 & 73.81 \\
Belgium & 41.03 & 19.39 & 21.91 & 75.65 \\
Denmark & 40.18 & 13.97 & 16.51 & 76.44 \\
France & 37.32 & 15.54 & 30.70 & 75.80 \\
Germany & 45.03 & 15.52 & 15.17 & 67.10 \\
Greece & 48.36 & 19.95 & 19.58 & 78.78 \\
Italy & 43.82 & 17.93 & 29.63 & 62.16 \\
The Netherlands & 42.68 & 14.90 & 17.49 & 76.49 \\
Spain & 45.21 & 23.79 & 27.39 & 65.09 \\
Sweden & 40.92 & 14.34 & 16.73 & 71.58 \\
Switzerland & 33.19 & 12.80 & 17.57 & 72.12 \\
\hline Total & 42.46 & 17.29 & 20.50 & \\
\hline
\end{tabular}

Table 4.3: Health indicators Part 2

Note: Entries are in percent.

\begin{tabular}{|l|c|c|c|}
\hline Country & Age 50-54 & Age 55-59 & Age 60-64 \\
\hline Austria & 82.35 & 65.35 & 16.77 \\
Belgium & 79.72 & 51.10 & 18.99 \\
Denmark & 84.05 & 78.26 & 56.49 \\
France & 87.66 & 60.87 & 7.87 \\
Germany & 83.04 & 77.04 & 39.37 \\
Greece & 92.42 & 77.96 & 44.97 \\
Italy & 85.34 & 56.28 & 29.21 \\
The Netherlands & 87.00 & 78.13 & 29.57 \\
Spain & 85.37 & 77.30 & 40.54 \\
Sweden & 93.85 & 82.86 & 67.83 \\
Switzerland & 93.75 & 92.65 & 72.00 \\
\hline Total & 86.33 & 71.18 & 38.20 \\
\hline
\end{tabular}

Table 4.4: Labour force participation men

Note: Entries are in percent. 


\begin{tabular}{|l|c|c|c|}
\hline Country & Age 50-54 & Age 55-59 & Age 60-64 \\
\hline Austria & 67.77 & 38.36 & 11.28 \\
Belgium & 59.79 & 30.15 & 7.58 \\
Denmark & 85.92 & 73.62 & 29.46 \\
France & 68.67 & 58.82 & 16.82 \\
Germany & 78.05 & 60.91 & 23.05 \\
Greece & 40.64 & 28.66 & 15.28 \\
Italy & 47.31 & 28.29 & 7.97 \\
The Netherlands & 61.70 & 49.53 & 17.24 \\
Spain & 47.57 & 40.53 & 19.02 \\
Sweden & 84.96 & 79.87 & 62.40 \\
Switzerland & 79.80 & 69.44 & 47.76 \\
\hline Total & 64.35 & 50.00 & 22.65 \\
\hline
\end{tabular}

Table 4.5: Labour force participation women Note: Entries are in percent.

\begin{tabular}{|l|c|c|c|}
\hline Country & Nonparticipation & Half time & Full time \\
\hline Austria & 49.9 & 2.5 & 47.7 \\
Belgium & 46.4 & 7.5 & 46.1 \\
Denmark & 27.1 & 7.2 & 65.7 \\
France & 41.6 & 4.8 & 53.6 \\
Germany & 35.8 & 4.8 & 59.5 \\
Greece & 32.6 & 13.4 & 54.0 \\
Italy & 48.7 & 9.5 & 41.8 \\
The Netherlands & 35.1 & 12.8 & 52.1 \\
Spain & 35.4 & 7.3 & 57.3 \\
Sweden & 19.3 & 8.5 & 72.2 \\
Switzerland & 17.9 & 9.9 & 72.2 \\
\hline Total & 36.0 & 8.2 & 55.8 \\
\hline
\end{tabular}

Table 4.6: Labour supply choice men Note: Entries are in percent. 


\begin{tabular}{|l|c|c|c|}
\hline Country & Nonparticipation & Half time & Full time \\
\hline Austria & 65.3 & 14.1 & 20.6 \\
Belgium & 65.9 & 19.4 & 14.7 \\
Denmark & 35.9 & 21.2 & 42.9 \\
France & 48.7 & 15.5 & 35.8 \\
Germany & 46.3 & 26.2 & 27.6 \\
Greece & 73.0 & 9.1 & 17.9 \\
Italy & 75.9 & 9.7 & 14.4 \\
The Netherlands & 55.6 & 31.0 & 13.4 \\
Spain & 64.4 & 9.8 & 25.8 \\
Sweden & 24.6 & 23.2 & 52.3 \\
Switzerland & 35.7 & 31.5 & 32.8 \\
\hline Total & 54.5 & 19.4 & 26.1 \\
\hline
\end{tabular}

Table 4.7: Labour supply choice women Note: Entries are in percent. 


\begin{tabular}{|c|c|c|c|c|c|c|}
\hline & Austria & Belgium & Denmark & France & Germany & Greece \\
\hline \multicolumn{7}{|l|}{ Age dummies } \\
\hline Age51 & -0.26 & -0.02 & -0.09 & 0.23 & -0.21 & -0.04 \\
\hline Age52 & -0.08 & -0.06 & 0.01 & 0.09 & -0.25 & 0.04 \\
\hline Age53 & -0.10 & 0.02 & -0.19 & -0.19 & -0.24 & -0.06 \\
\hline Age54 & -0.30 & 0.01 & -0.12 & 0.15 & -0.06 & -0.21 \\
\hline Age55 & -0.15 & -0.08 & -0.07 & -0.26 & -0.04 & -0.10 \\
\hline Age56 & -0.44 & -0.26 & 0.06 & -0.26 & -0.17 & -0.19 \\
\hline Age57 & -0.32 & -0.29 & -0.19 & -0.31 & -0.27 & -0.29 \\
\hline Age58 & -0.30 & -0.35 & -0.12 & -0.34 & -0.31 & -0.29 \\
\hline Age59 & -0.36 & -0.46 & -0.13 & -0.41 & -0.31 & -0.48 \\
\hline Age60 & -0.46 & -0.49 & -0.04 & -0.66 & -0.44 & -0.48 \\
\hline Age61 & -0.57 & -0.50 & -0.24 & -0.67 & -0.63 & -0.47 \\
\hline Age62 & -0.59 & -0.51 & -0.33 & -0.68 & -0.52 & -0.66 \\
\hline Age63 & -0.59 & -0.53 & -0.51 & & -0.56 & -0.60 \\
\hline Age64 & -0.58 & -0.53 & -0.58 & -0.65 & -0.62 & -0.76 \\
\hline \multicolumn{7}{|c|}{ Health related variables } \\
\hline Severe condition & -0.31 & -0.14 & -0.21 & -0.18 & -0.13 & -0.05 \\
\hline Mild condition & -0.04 & -0.05 & 0.03 & 0.03 & -0.08 & 0.04 \\
\hline ADL & -0.12 & -0.07 & -0.15 & -0.13 & -0.12 & -0.02 \\
\hline Obese & 0.01 & 0.04 & 0.07 & -0.05 & -0.09 & -0.01 \\
\hline Grip strength & 0.10 & 0.05 & 0.06 & 0.01 & 0.06 & 0.02 \\
\hline \multicolumn{7}{|c|}{ Demographic variables } \\
\hline Secondary edu. & 0.04 & 0.06 & 0.10 & 0.18 & 0.15 & 0.00 \\
\hline Higher edu. & 0.27 & 0.19 & 0.17 & 0.34 & 0.28 & 0.01 \\
\hline Children & 0.07 & 0.06 & 0.05 & 0.08 & 0.02 & 0.00 \\
\hline Couple & 0.13 & 0.10 & 0.17 & 0.08 & 0.00 & -0.08 \\
\hline Observations & 407 & 737 & 432 & 346 & 674 & 546 \\
\hline Prob. employed & 0.51 & 0.55 & 0.78 & 0.64 & 0.69 & 0.79 \\
\hline
\end{tabular}

Table 4.8: Marginal effects men Part 1

Note: Bold entries are significant at the five percent significance level. 


\begin{tabular}{|c|c|c|c|c|c|}
\hline & Italy & The Netherlands & Spain & Sweden & Switzerland \\
\hline \multicolumn{6}{|l|}{ Age dummies } \\
\hline Age51 & 0.04 & 0.04 & 0.23 & -0.02 & -0.08 \\
\hline Age52 & -0.22 & 0.09 & 0.06 & 0.01 & -0.05 \\
\hline Age53 & -0.04 & 0.05 & 0.13 & 0.08 & \\
\hline Age 54 & -0.13 & 0.04 & 0.10 & -0.01 & \\
\hline Age 55 & -0.23 & 0.02 & 0.15 & 0.02 & -0.05 \\
\hline Age 56 & -0.35 & 0.02 & -0.06 & -0.13 & -0.05 \\
\hline Age57 & -0.35 & -0.02 & -0.10 & -0.09 & -0.08 \\
\hline Age58 & -0.45 & -0.08 & 0.10 & -0.13 & 0.02 \\
\hline Age59 & -0.54 & -0.17 & 0.03 & -0.14 & \\
\hline Age60 & -0.55 & -0.42 & -0.37 & -0.23 & -0.14 \\
\hline Age61 & -0.50 & -0.38 & -0.36 & -0.23 & -0.22 \\
\hline Age62 & -0.56 & -0.52 & -0.15 & -0.21 & -0.15 \\
\hline Age63 & -0.59 & -0.67 & -0.28 & -0.33 & -0.33 \\
\hline Age64 & -0.52 & -0.59 & -0.36 & -0.33 & -0.50 \\
\hline \multicolumn{6}{|c|}{ Health related variables } \\
\hline Severe condition & -0.07 & -0.06 & -0.25 & -0.06 & -0.12 \\
\hline Mild condition & -0.01 & -0.05 & 0.01 & 0.00 & 0.01 \\
\hline $\mathrm{ADL}$ & 0.01 & -0.10 & -0.26 & -0.18 & -0.11 \\
\hline Obese & -0.13 & -0.04 & -0.05 & -0.02 & -0.03 \\
\hline Grip strength & -0.01 & 0.06 & 0.02 & 0.04 & 0.05 \\
\hline \multicolumn{6}{|c|}{ Demographic variables } \\
\hline Secondary edu. & 0.17 & 0.10 & 0.03 & 0.00 & 0.03 \\
\hline Higher edu. & 0.29 & 0.14 & 0.05 & 0.03 & 0.05 \\
\hline Children & 0.03 & 0.04 & 0.01 & 0.04 & 0.02 \\
\hline Couple & 0.10 & 0.09 & 0.08 & 0.13 & -0.02 \\
\hline Observations & 517 & 709 & 412 & 670 & 181 \\
\hline Prob. employed & 0.54 & 0.69 & 0.71 & 0.86 & 0.87 \\
\hline
\end{tabular}

Table 4.9: Marginal effects men Part 2

Note: Bold entries are significant at the five percent significance level. 


\begin{tabular}{|l|c|c|}
\hline Country & Men & Women \\
\hline Austria & 0.0 & 62.9 \\
Belgium & 0.4 & 0.0 \\
Denmark & 0.0 & 0.0 \\
France & 0.2 & 0.0 \\
Germany & 0.0 & 3.9 \\
Greece & 49.0 & 24.9 \\
Italy & 52.4 & 4.11 \\
The Netherlands & 0.0 & 0.0 \\
Spain & 0.0 & 1.36 \\
Sweden & 0.0 & 0.0 \\
Switzerland & 3.28 & 0.2 \\
\hline
\end{tabular}

Table 4.10: Probability values of no impact of health on participation Note: Entries are in percent. 


\begin{tabular}{|c|c|c|c|c|c|c|}
\hline & Austria & Belgium & Denmark & France & Germany & Greece \\
\hline \multicolumn{7}{|l|}{ Age dummies } \\
\hline Age51 & 0.01 & -0.03 & 0.05 & 0.09 & 0.07 & -0.07 \\
\hline Age52 & -0.06 & 0.02 & -0.17 & -0.10 & 0.14 & 0.08 \\
\hline Age53 & -0.15 & -0.14 & -0.07 & -0.12 & 0.17 & 0.06 \\
\hline Age54 & 0.08 & -0.19 & 0.17 & -0.02 & 0.16 & -0.11 \\
\hline Age55 & -0.22 & -0.20 & 0.02 & 0.04 & 0.12 & -0.21 \\
\hline Age56 & -0.07 & -0.21 & 0.04 & -0.16 & -0.12 & -0.14 \\
\hline Age57 & -0.25 & -0.31 & -0.03 & -0.14 & -0.11 & 0.02 \\
\hline Age58 & -0.24 & -0.29 & -0.19 & -0.29 & -0.13 & 0.03 \\
\hline Age59 & -0.30 & -0.25 & -0.34 & -0.30 & -0.12 & -0.12 \\
\hline Age60 & -0.34 & -0.36 & -0.36 & -0.41 & -0.33 & -0.18 \\
\hline Age61 & -0.29 & -0.32 & -0.57 & -0.49 & -0.37 & -0.15 \\
\hline Age62 & -0.35 & -0.33 & -0.54 & -0.53 & -0.36 & -0.09 \\
\hline Age63 & -0.35 & -0.37 & -0.56 & -0.51 & -0.39 & -0.27 \\
\hline Age64 & -0.38 & & -0.57 & -0.53 & -0.53 & -0.27 \\
\hline \multicolumn{7}{|c|}{ Health related variables } \\
\hline Severe condition & -0.11 & -0.08 & -0.18 & -0.28 & -0.08 & 0.02 \\
\hline Mild condition & -0.03 & -0.06 & -0.05 & -0.08 & -0.08 & -0.09 \\
\hline ADL & 0.02 & -0.04 & -0.09 & 0.03 & -0.09 & 0.01 \\
\hline Obese & -0.01 & -0.03 & 0.05 & -0.15 & 0.01 & 0.03 \\
\hline Grip strength & 0.01 & 0.08 & 0.11 & 0.03 & -0.03 & 0.03 \\
\hline \multicolumn{7}{|c|}{ Demographic variables } \\
\hline Secondary edu. & 0.08 & 0.01 & 0.11 & -0.06 & 0.07 & 0.00 \\
\hline Higher edu. & 0.33 & 0.20 & 0.31 & 0.13 & 0.17 & 0.26 \\
\hline Children & -0.02 & 0.00 & 0.03 & -0.07 & 0.00 & -0.01 \\
\hline Couple & -0.12 & -0.02 & 0.01 & -0.21 & -0.09 & -0.17 \\
\hline Observations & 475 & 735 & 434 & 427 & 776 & 552 \\
\hline Prob. employed & 0.30 & 0.33 & 0.70 & 0.50 & 0.54 & 0.27 \\
\hline
\end{tabular}

Table 4.11: Marginal effects women Part 1

Note: Bold entries are significant at the five percent significance level. 


\begin{tabular}{|c|c|c|c|c|c|}
\hline & Italy & The Netherlands & Spain & Sweden & Switzerland \\
\hline \multicolumn{6}{|l|}{ Age dummies } \\
\hline Age51 & 0.04 & 0.13 & -0.11 & 0.07 & -0.01 \\
\hline Age52 & 0.03 & 0.08 & -0.13 & -0.11 & -0.25 \\
\hline Age53 & 0.02 & 0.02 & -0.10 & 0.02 & -0.03 \\
\hline Age 54 & -0.07 & 0.03 & -0.18 & 0.02 & -0.10 \\
\hline Age 55 & -0.03 & 0.01 & -0.01 & -0.03 & -0.06 \\
\hline Age 56 & -0.15 & 0.00 & -0.22 & 0.04 & -0.32 \\
\hline Age57 & -0.13 & 0.06 & -0.17 & 0.02 & -0.40 \\
\hline Age58 & -0.11 & -0.13 & -0.11 & -0.08 & -0.32 \\
\hline Age59 & -0.14 & -0.06 & -0.09 & -0.03 & -0.18 \\
\hline Age60 & -0.23 & -0.33 & -0.13 & 0.00 & -0.36 \\
\hline Age61 & -0.20 & -0.30 & -0.26 & -0.21 & -0.40 \\
\hline Age62 & -0.22 & -0.25 & -0.33 & -0.09 & -0.26 \\
\hline Age63 & -0.21 & -0.40 & -0.16 & -0.32 & -0.56 \\
\hline Age64 & -0.23 & -0.32 & -0.33 & -0.34 & -0.56 \\
\hline \multicolumn{6}{|c|}{ Health related variables } \\
\hline Severe condition & -0.05 & -0.11 & 0.11 & -0.12 & 0.15 \\
\hline Mild condition & -0.07 & -0.07 & 0.00 & -0.07 & -0.06 \\
\hline $\mathrm{ADL}$ & 0.02 & -0.09 & -0.09 & -0.15 & -0.03 \\
\hline Obese & -0.09 & -0.19 & -0.04 & -0.02 & 0.17 \\
\hline Grip strength & 0.03 & 0.04 & 0.07 & 0.05 & 0.13 \\
\hline \multicolumn{6}{|c|}{ Demographic variables } \\
\hline Secondary edu. & 0.19 & 0.11 & 0.22 & 0.08 & 0.07 \\
\hline Higher edu. & 0.47 & 0.29 & 0.32 & 0.11 & 0.19 \\
\hline Children & -0.04 & 0.01 & 0.01 & 0.00 & -0.07 \\
\hline Couple & -0.16 & -0.07 & -0.19 & 0.02 & 0.03 \\
\hline Observations & 688 & 835 & 559 & 794 & 238 \\
\hline Prob. employed & 0.21 & 0.42 & 0.34 & 0.78 & 0.72 \\
\hline
\end{tabular}

Table 4.12: Marginal effects women Part 2

Note: Bold entries are significant at the five percent significance level. 


\begin{tabular}{|l|c|c|}
\hline Country & Current & Counterfactual \\
\hline Austria & 51.0 & 61.3 \\
Belgium & 54.6 & 61.5 \\
Denmark & 73.9 & 78.7 \\
France & 59.1 & 64.2 \\
Germany & 65.0 & 77.0 \\
Greece & 74.6 & 76.0 \\
Italy & 52.5 & 55.0 \\
The Netherlands & 65.3 & 72.6 \\
Spain & 66.7 & 78.9 \\
Sweden & 81.0 & 88.3 \\
Switzerland & 86.4 & 92.3 \\
\hline
\end{tabular}

Table 4.13: Men's estimated current and counterfactual participation rates Note: Entries are in percent.

\begin{tabular}{|l|c|c|}
\hline Country & Current & Counterfactual \\
\hline Austria & 34.9 & 35.9 \\
Belgium & 35.2 & 43.1 \\
Denmark & 64.7 & 74.4 \\
France & 51.8 & 61.9 \\
Germany & 54.3 & 62.1 \\
Greece & 30.6 & 36.3 \\
Italy & 26.2 & 33.1 \\
The Netherlands & 44.6 & 55.4 \\
Spain & 36.9 & 46.0 \\
Sweden & 76.0 & 89.1 \\
Switzerland & 67.6 & 68.4 \\
\hline
\end{tabular}

Table 4.14: Women's estimated current and counterfactual participation rates Note: Entries are in percent. 


\begin{tabular}{|l|c|c|c|c|c|c|}
\hline & \multicolumn{2}{|c|}{ Age 50-54 } & \multicolumn{2}{c|}{ Age 55-59 } & \multicolumn{2}{c|}{ Age 60-64 } \\
\hline & Current & Counterfact. & Current & Counterfact. & Current & Counterfact. \\
\hline Austria & 81.8 & 88.3 & 65.5 & 77.2 & 16.9 & 26.1 \\
Belgium & 79.9 & 84.6 & 51.1 & 59.5 & 19.4 & 27.4 \\
Denmark & 83.8 & 85.9 & 78.5 & 82.8 & 56.6 & 64.3 \\
France & 87.6 & 90.0 & 60.6 & 64.9 & 8.7 & 11.8 \\
Germany & 83.3 & 89.4 & 77.2 & 87.9 & 39.5 & 57.1 \\
Greece & 92.4 & 92.7 & 78.0 & 79.5 & 45.1 & 46.8 \\
Italy & 85.7 & 88.0 & 56.5 & 59.4 & 29.4 & 31.4 \\
The Netherlands & 87.2 & 91.0 & 78.1 & 84.5 & 29.8 & 38.3 \\
Spain & 86.0 & 92.0 & 77.1 & 87.5 & 40.9 & 59.9 \\
Sweden & 93.8 & 96.3 & 83.3 & 90.0 & 67.8 & 79.3 \\
Switzerland & 91.3 & 94.5 & 90.9 & 94.5 & 71.6 & 81.6 \\
\hline
\end{tabular}

Table 4.15: Men's estimated current and counterfactual participation rates Note: Entries are in percent.

\begin{tabular}{|l|c|c|c|c|c|c|}
\hline & \multicolumn{2}{|c|}{ Age 50-54 } & \multicolumn{2}{c|}{ Age 55-59 } & \multicolumn{2}{c|}{ Age 60-64 } \\
\hline & Current & Counterfact. & Current & Counterfact. & Current & Counterfact. \\
\hline Austria & 67.9 & 69.0 & 38.3 & 40.8 & 11.5 & 12.8 \\
Belgium & 59.8 & 66.2 & 30.3 & 39.5 & 9.2 & 14.8 \\
Denmark & 86.1 & 91.5 & 73.5 & 83.2 & 29.9 & 42.4 \\
France & 68.8 & 76.0 & 58.7 & 67.9 & 16.5 & 21.8 \\
Germany & 78.0 & 83.9 & 61.1 & 70.0 & 23.3 & 32.2 \\
Greece & 40.6 & 45.6 & 28.5 & 34.0 & 15.3 & 20.4 \\
Italy & 47.4 & 54.9 & 28.4 & 36.8 & 8.2 & 13.1 \\
The Netherlands & 61.5 & 71.3 & 49.6 & 62.9 & 17.3 & 26.5 \\
Spain & 47.4 & 55.6 & 40.6 & 50.3 & 19.2 & 28.6 \\
Sweden & 85.0 & 93.0 & 80.1 & 91.7 & 62.2 & 79.2 \\
Switzerland & 79.9 & 81.0 & 69.5 & 68.4 & 47.3 & 54.2 \\
\hline
\end{tabular}

Table 4.16: Women's estimated current and counterfactual participation rates Note: Entries are in percent. 


\begin{tabular}{|l|c|c|}
\hline & Men & Women \\
\hline Austria & 4.3 & 0.4 \\
Belgium & 5.5 & -1.6 \\
Denmark & 20.6 & 12.6 \\
France & 0.9 & -3.6 \\
Germany & 26.3 & 5.5 \\
Greece & 3.0 & 0.4 \\
Italy & -0.5 & -6.6 \\
The Netherlands & 8.2 & -1.4 \\
Spain & 28.8 & 4.3 \\
Sweden & 34.6 & 39.5 \\
Switzerland & 34.5 & 17.8 \\
\hline
\end{tabular}

Table 4.17: Decline in participation due to decline in health condition Note: Entries are in percent. 